\title{
O Acesso Aberto e a Economia Política da Publicação Científica
}

https://doi.org/10.21814/uminho.ed.43.11

\section{Paulo Serra}

LabCom - Comunicação e Artes, Faculdade de Artes e Letras, Universidade da Beira Interior, Portugal 



\section{Introdução}

Este texto trata do tema da publicação científica, mais precisamente, daquilo a que chamamos a economia política desse tipo de publicação e do lugar que nela deverá ter o acesso aberto. Do lugar que nela deverá ter o acesso aberto, dizemos. De facto, este não é um texto neutro, mas, um texto que defende explicitamente uma tese: a de que o acesso aberto, sob as suas diversas formas, deve ser a regra na publicação científica, eliminando-se progressivamente o acesso fechado.

A defesa dessa tese assenta em argumentos normativos, de que os principais são os dois seguintes: 1) sendo a ciência uma atividade eminentemente desenvolvida por instituições públicas, maioritariamente financiada com fundos públicos, os seus resultados devem também eles ser públicos, permitindo o acesso aos mesmos por parte de todos os cientistas e restantes cidadãos, Merton (1973) chamava, a esta norma, o comunismo da ciência; 2 ) tendo em conta o princípio de que quem trabalha deve ser remunerado pelo trabalho que faz, os cientistas não podem produzir um trabalho (como autores, editores, revisores) pelo qual não só não são remunerados, mas ainda têm de pagar, alimentando um paradoxo que não tem paralelo noutras áreas da atividade económica.

Os beneficiários das enormes mais-valias geradas pelas instituições públicas e pelos cientistas, na sua atividade de produção científica, são, como é bom de ver, os grandes conglomerados europeus e/ou estadunidenses de publicação que, nas últimas décadas, viram aumentar os seus lucros de forma exponencial, à medida que também foi aumentando de forma exponencial o volume da publicação nas revistas e editoras científicas que controlam. A chave mágica que permite uma tal apropriação capitalista chama-se "fator de impacto" (impact factor), um conceito introduzido por Eugene Garfield, em 1955, ainda que com objetivos diferentes de muitos daqueles em relação aos quais é atualmente utilizado, os quais devem ser questionados.

O corpo do texto que se segue encontra-se distribuído pelas seguintes secções: a economia política da publicação; as funções das revistas; a serials crisis e a revolta das universidades; o acesso aberto como resposta; alguns problemas do acesso aberto; para um acesso totalmente aberto. 0 texto termina com algumas considerações finais.

\section{A economia política da publicação}

De acordo com Mosco (2009), é possível definir economia política de duas maneiras diferentes, uma mais estreita e outra "mais geral e ambiciosa". De acordo com a primeira, "a economia política é o estudo das relações sociais, particularmente as relações de poder, que constituem mutuamente a produção, distribuição e consumo de 
recursos, incluindo os recursos da comunicação" (Mosco, 2009, p. 2). De acordo com a segunda, a economia política é "o estudo do controlo e da sobrevivência na vida social” (Mosco, 2009, p. 3). No que se segue, adotaremos a definição mais estreita e mais clássica da economia política, procurando analisar o que acontece com um tipo especial de recurso, a comunicação científica.

Falar de comunicação científica é falar, também, de um tipo especial de economia política. A economia política clássica - que tem, em Marx, o seu expoente -, centra-se no estudo do capitalismo industrial, vendo o trabalho como fonte de valor e sendo a fábrica o seu lugar de eleição. Já a economia política contemporânea centra-se no estudo do capitalismo cognitivo, que pode ser definido como "um modo de acumulação em que o objeto de acumulação consiste principalmente em conhecimento, que se torna a fonte básica de valor, bem como a localização principal do processo de valorização" (Boutang, 2011, p. 57), sendo o seu lugar de eleição, a universidade.

A consciência desta viragem da fábrica para a universidade, resumamo-la assim, é patente em várias obras publicadas, na década de 60 e na década de 70 do século XX, nomeadamente The production and distribution of knowledge in the United States, de Fritz Machlup (1962), The new industrial state, de John K. Galbraith (1967), The age of discontinuity, de Peter Drucker (1969), La societé post-industrielle, de Alain Touraine (1969), The coming of the post-industrial society, de Daniel Bell (1973), The information economy, de Marc Porat (1977) ou The third wave, de Alvin Toffler (1980).

Tendo em conta os conceitos anteriores, a questão que orienta este texto pode ser formulada do seguinte modo: como se produz, distribui e consome o conhecimento científico? Como veremos, na secção seguinte, a partir do século XVII, as revistas científicas (journals) vão ter um papel cada vez mais central em todo esse processo - não apenas no consumo, mas, porque este acaba por ter uma relação dialética com a produção também nas outras duas esferas: tal como só se produz aquilo que é necessário ao consumo, só se consome aquilo que já foi produzido; entre uma e outra a distribuição efetua a intermediação indispensável.

\section{As funções das revistas}

Os principais motivos de Henry Oldenburg para criar a revista The Philosophical Transactions of the Royal Society of London (1665) foram proteger a propriedade intelectual de autores/cientistas e também estabelecer um sistema de revisão científica (referee system; Guédon, 2001; Zuckerman \& Merton, 1971) - e não, propriamente, o desejo de tornar a ciência pública e acessível, obedecendo à norma do "comunismo" que constitui, para Merton (1973), uma das principais exigências do ethos científico. 
Com Eugene Garfield e a sua criação do ISI (Institute for Scientific Knowledge) e do fator de impacto (1955), surge um outro motivo: avaliar a ciência, definindo a core science através da definição de um conjunto de core journals (Guédon, 2001). Esses core journals serão avaliados e comparados entre si, precisamente, através do fator de impacto, calculado através da divisão entre o número de citações que os artigos de uma revista $X$ tiverem no ano $n$ pela soma dos números de artigos que essa revista $X$ publicou nos anos $n-1$ e $n$-2. Deste modo, como sublinha Guédon (2001) "estamos a pagar não tanto pela informação, mas sobretudo, pela avaliação" (p. 24).

As citações medem a maior ou menor atenção que o trabalho publicado pelos cientistas nas revistas ganha por parte de outros cientistas e que é cristalizado como reputação. É possível, assim, descrever a ciência como uma indústria baseada na economia da atenção em que a atenção constitui a medida do valor da informação científica (Franck, 1999, 2002). Por conseguinte, se no capitalismo cognitivo o conhecimento - a informação científica - é a fonte do valor, a medida desse valor será a atenção: "a atenção que uma teoria atrai é uma medida do seu valor como um bem de capital" (Franck, 2002, p. 3).

Deste modo, as revistas "funcionam realmente como um dispositivo com uma tripla função: ferramenta de marca (branding), chave para o título de propriedade, e instrumento de avaliação dos cientistas individuais" (Guédon, 2001, p. 31). Tendo em conta esta tripla função, "há, sem dúvida, core journals, bem conhecidos, que oferecem um bom valor, ao contrário do que acontece com revistas mais obscuras" (Guédon, 2001, p. 31).

Ora, a utilização do fator de impacto para avaliar cientistas individuais e não revistas representou, segundo Garfield (2006), uma evolução no sentido errado:

o termo "fator de impacto" evoluiu, gradualmente, para descrever quer o impacto da revista, quer o do autor. Os fatores de impacto das revistas envolvem, geralmente, populações relativamente grandes de artigos e citações. Os autores individuais produzem, geralmente, pequenos números de artigos, embora alguns tenham publicado um número fenomenal. (p. 90)

No mesmo sentido, a Declaração de São Francisco sobre a Avaliação da Investigação (2012), aprovada por um grupo de diretores e editores de revistas académicas, em reunião havida por ocasião do "Annual Meeting of the American Society for Cell Biology” (ASCB), em São Francisco (Califórnia), em 16 de dezembro de 2012, recomenda que o fator de impacto da Thomson Reuters seja utilizado para avaliar revistas - finalidade para a qual foi criado -, e não para avaliar a qualidade dos artigos científicos e dos respetivos investigadores. Até porque, como também sublinha Alberts, "é sempre possível publicar um artigo que nunca será citado por alguém numa revista com alto fator de impacto" (Pivetta \& Marques, 2012, para. 7). 
Este problema da utilização do fator de impacto das revistas como critério de avaliação dos investigadores individuais agrava-se, ainda, se pensarmos na proliferação recente e crescente de editores e revistas predatórios, em que os autores pagam pela publicação de artigos que muitas vezes nem sequer são revistos e que anunciam fatores de impacto que são falsos ou manipulados. Como diz Jeffrey Beall (2018), "sistemas de avaliação académica que ainda analisam apenas o número de artigos publicados por um determinado cientista também ajudam a fazer prosperar a corrupção" (p. 1).

A única maneira de avaliar com segurança os artigos de um autor seria, de acordo com Garfield (2006), que os avaliadores lessem todos os seus artigos e avalisassem cada um deles individualmente. Ora, dada a dificuldade e morosidade de um tal processo, uma prática que tem vindo a ser utilizada, por exemplo, nos EUA, é a de que os avaliadores façam a leitura e avaliação apenas dos cinco artigos que o autor indique como os seus mais importantes (Alberts, como citado em Pivetta \& Marques, 2012) ${ }^{1}$.

\section{A serials crisis e a revolta das universidades}

Estando latente há várias décadas, o problema designado pela expressão serials crisis ${ }^{2}$ tem vindo a ganhar cada vez mais importância e visibilidade no domínio da publicação científica e universitária. Como se sabe, a expressão em causa é geralmente usada "para destacar o aumento exponencial no custo da subscrição de muitas revistas académicas, particularmente as que são publicadas por editores que visam o lucro" (Das, 2015, p. 44).

As razões dessa crise serão várias incluindo os cortes orçamentais das universidades e das suas bibliotecas, os preços cada vez mais elevados das revistas e dos artigos, a própria recessão económica (Das, 2015, p. 44). Essa crise é também vista como uma das causas que levaram à expansão do movimento de acesso aberto, tendo em vista "ajudar os investigadores a ultrapassar a sua dependência excessiva das companhias monopolistas de edição” (Das, 2015, p. 44).

$\mathrm{Na}$ impossibilidade de fazermos aqui uma história detalhada do processo da serials crisis, referiremos apenas alguns episódios recentes que consideramos mais determinantes e, ao mesmo tempo, mais simbólicos.

Um desses episódios é o protagonizado pela Universidade de Harvard, em 2012. Considerando incomportáveis os preços praticados por editoras de revistas científicas

\footnotetext{
${ }^{1}$ Esta é uma prática também hoje corrente em Portugal em provas e concursos da carreira académica.

${ }^{2}$ A expressão poderia ser traduzida por "crise das publicações em série"; no entanto, dada a sua utilização generalizada no original Inglês, optámos pela sua não tradução.
} 
como a Elsevier, a Springer e a Wiley, aquela que é geralmente considerada como uma das mais ricas e prestigiadas instituições do mundo decidiu encorajar os seus investigadores a publicar o seu trabalho em revistas de acesso aberto e a deixarem de publicar e de exercer atividades editoriais e de revisão em revistas de acesso fechado (Sample, 2012). Como na altura referiu Robert Darnton, diretor da Biblioteca de Harvard:

espero que outras universidades adotem ações similares. Todos nós enfrentamos o mesmo paradoxo. Fazemos a investigação, escrevemos os artigos, revemos artigos de outros investigadores, desenvolvemos atividades em conselhos editoriais, tudo de graça... e depois compramos de volta os resultados do nosso trabalho a preços exorbitantes. (Sample, 2012, para. 7)

E, de facto, esta posição da Universidade de Harvard e de Darnton tem vindo a ser seguida por várias universidades, nos EUA e noutros pontos do mundo, nomeadamente na Europa. Um dos episódios mais recentes (já em 2019) foi o rompimento da Universidade da Califórnia com a Elsevier, motivado não só pelos preços exorbitantes praticados pela editora, mas também pelo comprometimento da universidade com o acesso aberto e universal ao conhecimento científico (UC Office of the President, 2019).

Numa iniciativa liderada pela Comissão Europeia e desencadeada pela Science Europe, um grupo de agências de financiamento da investigação cientifica de 11 países europeus - Áustria, Eslovénia, França, Holanda, Irlanda, Itália, Luxemburgo, Noruega, Polónia, Reino Unido, Suécia - lançou em 4 de setembro de 2018 o Plano $\mathrm{S}^{3}$, que obriga a que, a partir de 2020 , "os cientistas que elas financiam tornem os artigos resultantes livres para serem lidos imediatamente após a publicação. Os artigos teriam uma licença de publicação liberal que permitiria a qualquer pessoa baixar, traduzir ou reutilizar o trabalho" (Else, 2018, p. 17).

Mas a questão do preço não é a única que suscita preocupações em relação às editoras científicas e académicas. Assim, em 26 de outubro de 2018, a European University Association (EUA) elaborou um documento, a enviar à Direção-Geral da Concorrência da União Europeia, intitulado "Preocupações das universidades europeias com a falta de competição no setor de publicações académicas". No documento, a EUA pede a intervenção das autoridades europeias no apuramento das seguintes questões relativas às editoras a académicas:

1. elevado grau de concentração da propriedade;

2. um setor com estruturas oligopolísticas;

\footnotetext{
${ }^{3}$ Ver https://www.coalition-s.org/
} 
3. ausência de transparência na definição de preços;

4. grandes lucros com base em fundos públicos;

5. Solicitações de acesso aberto sem efeitos positivos nos preços;

6. assimetria no poder de negociação;

7. tendência para bloqueio de fornecedor;

8. ausência de sinais de melhoria na competição. (EUA, 2018, p. 2)

Para caracterizar o modelo de negócios das editoras académicas, a EUA recorre à seguinte alegoria bem conhecida: "imagine um agricultor que possui, alimenta e ordenha a sua vaca para dar o leite de graça a uma empresa de laticínios - e então, finalmente, compra-o de volta numa caixa de leite a um preço muito elevado" (EUA, 2018 , p. 1). De forma menos alegórica, "o paradoxo que alimenta a indústria tradicional da publicação científica” pode formular-se do seguinte modo:

o resultado da investigação que é produzida pelo aparelho científico dos países com recurso a fundos públicos, é oferecido gratuitamente às editoras, que por sua vez o revenderão à comunidade científica, captando ainda mais recursos públicos. (Gradim, 2015, pp. 113-114)

0 acesso aberto tem sido visto, precisamente, como uma forma de resposta a esse paradoxo - ainda que tal resposta não deixe de envolver as suas próprias questões.

\section{0 acesso aberto como resposta}

A primeira das questões tem a ver com a própria definição de acesso aberto até porque há várias formas de acesso aberto. De acordo com a definição de Suber (2012), "a literatura em acesso aberto (AA) é digital, em linha, gratuita e isenta da maior parte das restrições de direitos de autor e de licenciamento” (p. 4). Ainda segundo Suber,

o AA foi definido em três declarações públicas influentes: a Iniciativa de Acesso Aberto de Budapeste (fevereiro de 2002), a Declaração de Bethesda sobre Publicação de Acesso Aberto (junho de 2003) e a Declaração de Berlim sobre Acesso Aberto ao Conhecimento nas Ciências e Humanidades (outubro de 2003). Às vezes, refiro-me à sua sobreposição ou pontos comuns como a definição BBB de AA. (Suber, 2012. p. 7)

A segunda das questões tem a ver com a distinção entre os vários tipos de acesso aberto, em função de certos critérios. Duas das principais distinções são as seguintes: 
1) tendo em conta o tipo de barreiras (de preço e de permissão), podemos ter acesso aberto grátis (gratis $O A$ [open access]) e acesso aberto livre (libre $O A$ ): enquanto, no primeiro, removemos apenas as barreiras de preço, no segundo, removemos também pelo menos algumas barreiras de permissão (Suber, 2012, p. 6); 2) tendo em conta a existência ou não de revisão por pares, podemos ter acesso aberto dourado (gold $O A$ ), relativo a revistas, com revisão por pares, e acesso aberto verde (green $O A$ ), relativo a repositórios, sem revisão por pares, mas que podem incluir textos revistos/publicados noutras instâncias, por exemplo, revistas (Suber, 2012, p. 6). Refira-se, a propósito, que o acesso aberto verde tornou-se, já há alguns anos, obrigatório para os investigadores que desenvolvem projetos financiados pela União Europeia, nomeadamente no âmbito do Horizonte2020 (Comissão Europeia, 2017), e pela Fundação para a Ciência e a Tecnologia portuguesa (FCT, 2014).

A terceira questão é que acesso aberto não é sinónimo de acesso universal, dado que ele não elimina outros tipos de barreiras, nomeadamente as de filtragem e censura (países, governos, empresas, etc.), linguísticas (apesar da tradução automática), de acesso a pessoas portadoras de deficiência (embora elimine algumas) e de conetividade (a divisão digital; Suber, 2012, p. 27).

Note-se, ainda, que o acesso aberto é compatível com a maior parte das condições que são garantidas pelo acesso fechado, nomeadamente direitos de autor, revisão por pares, receitas (e mesmo lucros), impressão, preservação, prestígio, qualidade, progressão na carreira e indexação (Suber, 2015).

Dadas as suas características, o acesso aberto apresenta um conjunto de benefícios potenciais para os investigadores, nomeadamente o aumento da visibilidade, da utilização e do impacto dos resultados da sua investigação, bem como a criação de ligações permanentes para esses resultados (Tsoukala \& Angelaki, 2015, p. 5).

\section{Alguns problemas do acesso aberto}

Apesar das suas vantagens para instituições de investigação e investigadores, em matéria de publicação científica, o acesso aberto apresenta vários problemas. Um desses problemas são os editores predatórios (predatory editors), primeiramente postos em evidência por Jeffrey Beall (2013), que os define como "editores de acesso aberto que exploram o modelo de acesso aberto dourado apenas para seu próprio lucro, fingindo ser operações de publicação legítimas, mas aceitando de fato todas e quaisquer submissões apenas pelo dinheiro" (p. 591).

Segundo Beall (2017a), os primeiros exemplos deste tipo de editores terão surgido em 2008, no Paquistão, levando-o a cunhar a expressão para os designar, em 2010 (p. 285), e a iniciar a publicação da lista de editores predatórios no blogue Posterous (Beall, 2017b, p. 274). Entre janeiro de 2012 e janeiro de 2017, Beall manteve, no 
blogue Scholarly Open Access, criado para o efeito, uma lista de editores e revistas predatórios, atualizada à medida que ia descobrindo novos exemplos; de acordo com a sua versão, Beall terá encerrado o blogue, em janeiro de 2017, devido às pressões sofridas por parte do seu empregador de então, a Universidade de Colorado Denver, e ao consequente medo de perder o emprego (Beall, 2017b, p. 273).

O que é certo é que, ao longo dos anos, a lista de Beall não foi parando de crescer: de 18 editores predatórios, em 2011, para 1.185, em 2017; de 126 revistas predatórias independentes, em 2013, para 1.294, em 2017 (Oliveira, 2017).

Os editores e revistas predatórios são, no entender de Beall, um efeito direto do acesso aberto dourado (gold open access), que carateriza, também, como o "modelo autor-paga" - na medida em que os custos da publicação são transferidos dos subscritores dos artigos para os autores dos mesmos (ou para as instituições que os financiam), tendo os primeiros acessos gratuitos aos artigos: "essa aceitação gradual do modelo de acesso dourado levou à criação de editores predatórios, aqueles que exploram o modelo para seu próprio lucro" (Beall, 2017a, p. 284).

Assim, o que o modelo do acesso aberto dourado, pago pelos autores, faz, no fundo, é transferir os custos da publicação científica dos editores tradicionais, baseados na subscrição, para os editores predatórios; ou seja, "o movimento de acesso aberto está a lidar com a serials crisis reduzindo ou eliminando as taxas de assinatura que as bibliotecas têm de pagar" (Beall, 2013, p. 593), não os custos dos autores ou das suas instituições de pertença ou mesmo dos governos.

Ora, na perspetiva de Beall, esta prática de transferência do pagamento da publicação para os autores interessados em publicar - o chamado article processing charge (APC) - "está a corromper a publicação académica" (Beall, 2013, p. 593). Essa corrupção traduz-se, principalmente, no facto de que, para terem o maior lucro possível, os editores predatórios tendem a tornar pouco rigorosa ou mesmo a eliminar a revisão por pares dos artigos das suas revistas: "um dos aspetos mais negativos das revistas predatórias é sua incapacidade de realizar uma revisão por pares padrão, baseada na ciência" (Beall, 2017b, p. 285).

Deste modo, os editores e revistas predatórios, bem como o acesso dourado que os sustenta, constituem "a maior ameaça à ciência desde a Inquisição", na medida em que falham "em demarcar a ciência autêntica da ciência metodologicamente insana, permitindo que a ciência falsificada (...) se apresente como se fosse ciência autêntica” (Beall, 2017b, p. 276).

No entanto, como Beall sublinha em vários dos seus textos, o problema não está propriamente no acesso aberto em si mesmo, mas no acesso dourado pago pelos autores. Como afirma em texto recente: 
não há nada intrinsecamente errado com o modelo de publicação de acesso aberto, mas para ser bem-sucedido, ele deve ser gerido adequadamente, de uma forma que beneficie a ciência, aqueles que realizaram e relataram a investigação e os leitores e outros "consumidores" da investigação. Nem todas as revistas de acesso aberto são predatórias, nem todas as revistas por subscrição são de elevada qualidade. (Beall, 2018, p. 1)

Precisamente para distinguir o acesso dourado predatório do "verdadeiro" acesso aberto - livre para os leitores e para os autores -, Beall (2015) propõe, para este último, a designação de "acesso aberto de platina" (platinium OA; p. 15), havendo autores que propõem outras designações, como é o caso de Fuchs e Sandoval (2013) que propõem chamar-lhe acesso aberto de diamante (diamond $O A$ ).

A sua oposição determinada ao acesso aberto (dourado) leva Beall a afirmações extremas e claramente ideológicas como a de que os defensores do acesso aberto "querem coletivizar tudo e eliminar o negócio privado" (Beall, 2013, p. 589), de que o acesso aberto é "uma tentativa neocolonial", por parte da Europa e da sua minoria coletivista, financiada pelo "esquerdista" George Soros (Beall, 2013, p. 592), ou ainda de que o acesso aberto "é um tipo de colonialismo" que pretende invadir a "indústria da publicação académica” (Beall, 2018, p. 2).

Apesar de não subscrevermos estas e outras teses de Beall, que parece atribuir pouco relevo a questões essenciais como as da serials crisis, da concentração e do monopólio editoriais, da falta de transparência na fixação de preços ou dos conflitos de interesses (de que são exemplos os que afetam a Elsevier, que é ao mesmo tempo uma editora de revistas e uma avaliadora dessas revistas), há, na sua crítica ao acesso aberto, pelo menos duas exigências que não podem ser iludidas: a primeira, a de que o acesso aberto não pode dispensar a revisão por pares; a segunda, a de que para haver acesso aberto, alguém terá de pagar os custos da publicação científica. 0 mesmo é dizer que o acesso aberto, para o ser verdadeiramente, terá de assegurar um financiamento que não passe pelo pagamento de taxas de publicação pelos autores dos artigos.

\section{Para um acesso totalmente aberto}

Coloca-se, assim, a questão de saber como garantir o financiamento do acesso aberto sem que tal implique a ditadura económica quer dos editores tradicionais (Elsevier, Springer, Wiley, etc.), quer dos novos editores predatórios. Uma possível resposta a esta questão é-nos sugerida pelo próprio Jeffrey Beall (2018):

há muitas comunidades unidas de investigadores, centrados num campo ou subcampo, que editam revistas de maneira cooperativa - tanto por assinatura quanto por acesso aberto - e cujo voluntarismo e controlo editorial 
rígido fazem com que cada uma dessas revistas apoiadas pela comunidade seja bem-sucedida. Essas comunidades permitem uma comunicação eficaz e significativa entre pares, e tais revistas deveriam ser modelos para todos os campos académicos. (p. 3)

Estas "comunidades unidas", de que fala Beall, podem ser encontradas ou formadas ao nível de várias instâncias do trabalho académico e cuja importância relativa é variável de país para país e mesmo de universidade para universidade: unidades ou grupos de investigação e desenvolvimento (I\&D); programas de pós-graduação; departamentos e faculdades; associações científicas (por exemplo, a Sociedade Brasileira de Estudos Interdisciplinares da Comunicação [Intercom] ou a Associação Portuguesa de Ciências da Comunicação [Sopcom]). Estas instâncias, isoladas ou em associação, podem propiciar os recursos financeiros e humanos necessários à publicação de revistas científicas em acesso totalmente aberto sem custos, nem para os autores nem para os utilizadores, garantindo todas as condições de exigência a que uma revista científica deve obedecer, a começar pela revisão por pares.

Os exemplos de que tal é possível são vários, em várias latitudes e áreas científicas. Assim, ao examinar um conjunto de 437 revistas científicas de acesso aberto, publicadas nos cinco países nórdicos (Dinamarca, Finlândia, Islândia, Noruega e Suécia), Björk (2019) constata que $53 \%$ são publicadas por universidades, departamentos de universidades ou editoras de universidades, institutos governamentais, fundações; outros $39 \%$ por sociedades científicas, seja no website da sociedade, num portal não comercial ou por um editor comercial; $4 \%$ por editores puramente comerciais e ainda $4 \%$ por académicos independentes não ligados diretamente a universidades ou sociedades científicas (p. 4). Björk (2019) constata, ainda, que apenas 19 revistas exigiam pagamento de APC, sendo que 11 eram da área da Medicina ou Biologia e 10 eram publicadas por editores comerciais (p. 6).

Algo semelhante acontece com muitas das revistas da área das Ciências da Comunicação, no Brasil e em Portugal, muitas das quais até se encontram indexadas em bases de dados como a Web of Science (WoS), a SciELO ou a Scopus.

Com esta forma de financiamento e gestão da publicação, é também possível ultrapassar uma das outras críticas que os opositores ao acesso aberto dourado pago costumam apresentar: a de que ele favoreceria os autores, as instituições e os países mais ricos: não tendo de pagar por isso, todos podem publicar, sejam (mais) ricos ou (mais) pobres - a questão é que os revisores reconheçam a devida qualidade ao seu trabalho.

Para além dos recursos financeiros e humanos, estas revistas precisam de garantir também conselhos editoriais e revisores competentes, diversificados, em número 
suficiente e pontuais - algo que, dada a multiplicação das revistas em cada uma das áreas e subáreas científicas, nem sempre é fácil assegurar em regime pro bono.

Apesar das dificuldades, o acesso aberto dourado, maioritariamente não envolvendo pagamento pelos autores, tem crescido de forma continuada. Assim, referindo-se apenas às revistas indexadas no Directory of Open Access Journals (DOAJ), Crawford (2019) regista o seguinte crescimento do número de artigos publicados entre 2013 e 2018: 416.251, em 2013; 490.277, em 2014; 541.700, em 2015; 595.707, em 2016; 651.384, em 2017 e 711.670, em 2018; acrescente-se, ainda, que das revistas indexadas no DOAJ apenas 30\% exigiam, em 2018, pagamento de taxa de publicação (p. 1) ${ }^{4}$.

Outra questão que se coloca às revistas em acesso totalmente aberto, e que aqui só podemos tratar de forma breve, é o da sua indexação e avaliação em termos de impacto. Como referimos atrás, o acesso aberto não é impeditivo da indexação destas revistas em bases de dados, como a WoS ou a Scopus, e da consecução de bons fatores de impacto. Deste modo, comparando 610 revistas em acesso aberto com 7.609 revistas por subscrição, utilizando os dados da Web of Science, e 1.327 revistas em acesso aberto com 11.124 revistas por subscrição, utilizando os dados da Scopus, e sendo, em ambos os casos, os dados controlados por disciplina, idade da revista e localização do editor, Björk \& Solomon (2012) concluíam que "as revistas em acesso aberto indexadas na Web of Science e/ou Scopus estão a aproximar-se do mesmo impacto científico e qualidade que as revistas por subscrição, particularmente em biomedicina e para revistas financiadas por taxas de processamento de artigos" (p. 1).

Contudo, apenas uma pequena parte das revistas em acesso aberto pode vir a ser objeto de indexação na WoS ou na Scopus: de acordo com os dados de um estudo de Fuchs e Sandoval (2013), de uma amostra de 210 revistas indexadas na WoS, apenas 25 (11,9\%) eram revistas em acesso aberto (p. 431). Impõe-se, portanto, uma alternativa que abranja o conjunto das revistas em acesso aberto, de todas as áreas, em todas as línguas.

Uma das alternativas que têm vindo a ser discutidas é o Google Académico. No entanto, e para já, a controvérsia sobre essa alternativa é evidente.

Assim, Jeffrey Beall (2015) adota uma posição radicalmente contra o uso do Google Académico:

tenho vindo a considerar e a escrever sobre o valor do Google Scholar desde finais de 2014. Porque não efetua um rastreio de qualidade e pretende ser

\footnotetext{
${ }^{4}$ Sobre a evolução do acesso aberto dourado (DOA) entre 2011 e 2018, Crawford disponibiliza um precioso conjunto de livros e dados, incluindo o citado, em https://waltcrawford.name/goaj.html
} 
abrangente, o Google Scholar está cheio de ciência-lixo. Indexa - ao nível de artigo - artigos de alta qualidade e revistas predatórias, de modo que inclui no seu índice central todos os artigos de baixa qualidade e de pseudociência que os editores predatórios publicam com alegria em troca de um valor para o processamento dos textos. (p. 26)

Isto leva ainda Beall (2017a) a considerar que o Google "é talvez o maior índice mundial de ciência-lixo", sendo os seus malefícios potenciados pelo facto de que "é também o motor de pesquisa académica mais popular e acessível” (p. 293).

Num sentido contrário - ainda que reconhecendo algumas deficiências do Google Académico -, temos vários outros estudos e autores, de que referiremos aqui apenas alguns.

Utilizando uma amostra de 277 revistas da área de Ciências da Comunicação, Delgado e Repiso (2013) concluem que, relativamente à WoS e à Scopus, as métricas do Google Académico não só têm uma maior cobertura do que aquelas, incluindo mais revistas e em mais línguas que a inglesa, como também se revelam mais ou menos equivalentes em termos do cálculo do fator de impacto e do ranking das revistas, havendo uma alta correlação entre os seus resultados e os daqueles outros dois serviços (p. 51).

Por sua vez, Harzing ${ }^{5}$ e Alakangas (2015) incluem o estudo de Delgado e Repiso num conjunto de estudos que concluem, no geral, "que o Google Académico oferece uma cobertura mais ampla para a maioria das disciplinas e que a Web of Science e a Scopus fornecem resultados bastante semelhantes" (p. 788). 0 seu próprio estudo longitudinal, que compara a taxa de crescimento das publicações e das citações das três bases de dados, entre julho de 2013 e julho de 2015, conclui que "tanto o Google Académico quanto o Scopus a nosso ver se tornaram alternativas credíveis para a Web of Science" (Harzing \& Alakangas, 2015, p. 801). Contudo, as autoras não deixam de reconhecer alguns problemas do Google Académico, como sejam a falta de um processo de controlo de qualidade exigente, que o leva a indexar publicações de menor qualidade, e a existência de um grande número de artigos duplicados ou "citações perdidas" (stray citations; Harzing \& Alakangas, 2015, p. 802).

Ainda no mesmo sentido, Martín-Martín et al. (2018), ao estudarem as citações nas três bases de dados, concluem que "os resultados sugerem que, em todas as áreas, os dados de citação do Google Académico são, essencialmente, um superconjunto da WoS e da Scopus, com cobertura extra substancial" (p. 1160).

\footnotetext{
${ }^{5}$ Anne-Wil Harzing é a criadora do programa "Publish or Perish", que trabalha com base nos dados do Google Académico (Harzing, 2016; Harzing, 2017).
} 
No que diz respeito às chamadas "métricas alternativas" ao fator de impacto (altmetrics, article level metrics), diremos apenas que elas apresentam vários problemas: 1 ) relacionam-se sobretudo com o impacto social da investigação, não medindo especificamente o impacto científico; 2) apresentam limitações como o caráter evanescente das suas fontes, o agravamento dos tradicionais problemas bibliométricos de normalização e a possibilidade de manipulação dos indicadores (gaming altmetrics; Barros, 2015; Taberner, 2018, p. 96).

\section{Considerações finais}

Para além de ser uma questão de economia política, o acesso aberto envolve também aquilo a que Bacevic e Muellerleile (2017) chamam uma "economia moral", e que o é por uma dupla razão: em primeiro lugar, porque "o objetivo da troca (...) não é gerar lucro, mas sim gerar (mais) bem [o conhecimento]” (p. 180); em segundo lugar, porque "na medida em que o conhecimento se torna o bem final, ele está posicionado para além da esfera da troca de mercadorias” (p. 183).

Esse caráter moral do acesso aberto encontra um dos seus antepassados mais diretos e ilustres na Encyclopédie, ou Dictionnaire Raisonné des Sciences, des Arts et des Métiers (1751-1772), de Diderot e D’Alembert, que visava colocar todo o saber da época ao alcance de todos os homens, acreditando com isso trazer a todos a "luz da razão".

Sabemos, hoje, que a razão não é apenas luz, que ela também inclui as suas sombras, e que o homem está longe de se reduzir à razão, envolvendo também sentimento e emoção. No entanto, continua a haver uma diferença essencial entre a ignorância e o conhecimento: enquanto a primeira reduz e limita as nossas escolhas em termos não apenas instrumentais, mas também morais, só o conhecimento nos dá a possibilidade de aumentar e ampliar essas escolhas, para o bem e para o mal. Parecendo o mesmo, o sono dos justos não é da mesma natureza que o sono dos ignorantes.

Por isso mesmo, todas as estratégias que tendem a submeter o conhecimento a restrições económicas, políticas ou religiosas resultam no empobrecimento da vida de cada um dos homens e da humanidade no seu conjunto; e, como sabemos, as inquisições de hoje não são menos violentas que as de ontem, apenas adquiriram novas formas.

Que o caminho em direção ao acesso aberto ao conhecimento científico implique uma espécie de retrocesso - ao ideal iluminista -, isso só nos fornece mais uma ilustração de como, por vezes, o progresso histórico só é possível através de um recuo em direção ao passado - para recuperar, desse passado, possibilidades emancipatórias que foram esquecidas ou obliteradas por interesses particulares. 


\section{Referências}

Bacevic, J., \& Muellerleile, C. (2017). The moral economy of open access. European Journal of Social Theory, 21(2), 169-188. https://doi.org/10.1177/1368431017717368

Barros, M. (2015). Altmetrics: Métricas alternativas de impacto científico com base em redes sociais. Perspectivas em Ciência da Informação, 20(2), 19-37. https://doi.org/10.1590/1981-5344/1782

Beall, J. (2013). The open-access movement is not really about open access. tripleC, 11(2), 589-597. https:// doi.org/10.31269/triplec.v11i2.525

Beall, J. (2015). Os editores predatórios estão a destruir a integridade da comunicação académica. In A. Gradim \& C. Moura (Eds.), Comunicar e avaliar ciência (pp. 11- 30). LabCom.IFP. http://labcom.ubi.pt/livro/248

Beall, J. (2017a). Scientific soundness and the problem of predatory journals. In A. B. Kaufman \& J. C. Kaufman (Eds.), Pseudoscience: The conspiracy against science (pp. 283-299). The MIT Press.

Beall, J. (2017b). What I learned from predatory publishers. Biochemia Medica, 27(2), 273-279. https://doi. org/10.11613/BM.2017.029

Beall, J. (2018). Invited comment: Predatory journals exploit structural weaknesses in scholarly publishing. 4open,1(1), 1-3. https://doi.org/10.1051/fopen/2018001

Björk, B.-C. (2019). Open access journal publishing in the Nordic countries. Learned Publishing, 32, 227-236. https://doi.org/10.1002/leap.1231

Björk, B.- C., \& Solomon, D. (2012). Open access versus subscription journals: A comparison of scientific impact. BMC Medicine, 10, 1-10. https://doi.org/10.1186/1741-7015-10-73

Boutang, Y. M. (2011). Cognitive capitalism. Polity Press.

Comissão Europeia. (2017). Guidelines to the rules on open access to scientific publications and open access to research data in Horizon 2020 (Version 3.2). https://ec.europa.eu/research/participants/data/ref/h2020/ grants_manual/hi/oa_pilot/h2020-hi-oa-pilot-guide_en.pdf

Crawford, W. (2019). Gold open access 2013-2018: Articles in journals (GOA4). Cites \& Insights Books. https:// waltcrawford.name/goa4.pdf

Das, A. K. (2015). The serials crisis. In S. Mishra \& M. P. Satija (Eds.), Unesco curriculum for researchers, module 1: Scholarly communications (pp. 44-67). Unesco. http://eprints.rclis.org/24811/1/R1.4\%20Serial_Crisis.pdf

Declaração de São Francisco sobre a Avaliação da Investigação, 16 de dezembro de 2012, https://sfdora. org/read/

Delgado, E., \& Repiso, R. (2013). The impact of scientific journals of communication: Comparing Google Scholar Metrics, Web of Science and Scopus. Comunicar, 21(41), 45-52. https://doi.org/10.3916/c41-2013-04

Else, H. (2018). Radical open-access plan could spell end to journal subscriptions. Nature, 561(7721), 17-18. https://doi.org/10.1038/d41586-018-06178-7 
European University Association. (2018). The lack of transparency and competition in the academic publishing market in Europe and beyond. https://eua.eu/news/188:scholarly-publishing-eua-asks-european-commission-to-investigate-lack-of-competition.html

Fundação para a Ciência e a Tecnologia. (2014). Política sobre acesso aberto a publicações científicas resultantes de projetos de I\&D financiados pela FCT. https://www.fct.pt/documentos/PoliticaAcessoAberto_Publicacoes.pdf

Franck, G. (1999). Scientific communication: A vanity fair? Science, 286(5437), 53-55. https://doi.org/10.1126/ science.286.5437.53

Franck, G. (2002). The scientific economy of attention: A novel approach to the collective rationality of science. Scientometrics, 55(1), 3-26. https://doi.org/10.1023/A:1016059402618

Fuchs, C., \& Sandoval, M. (2013). The diamond model of open access publishing: Why policy makers, scholars, universities, libraries, labour unions and the publishing world need to take non-commercial, non-profit open access serious. tripleC, 13(2), 428-443. https://doi.org/10.31269/triplec.v11i2.502

Garfield, E. (1955). Citation indexes for science: A new dimension in documentation through association of ideas. Science, 122, 108-111. http://garfield.library.upenn.edu/essays/v6p468y1983.pdf

Garfield, E. (2006). The history and meaning of the journal impact factor. JAMA, 295(1), 90-93. https://doi. org/10.1001/jama.295.1.90

Gradim, A. (2015). Editores predatórios e modelos de open access. In A. Gradim \& C. Moura (Eds.), Comunicar e avaliar ciência (pp. 111-126). LabCom.IFP. http://labcom.ubi.pt/livro/248

Guédon, J.-C. (2001). In Oldenburg's long shadow: Librarians, research scientists, publishers and the control of scientific publishing. Association of Research Libraries. https://www.arl.org/wp-content/uploads/2001/12/ in-oldenburgs-long-shadow.pdf

Harzing, A. W. (2016, 6 de fevereiro). Publish or perish. Harzing.com. https://harzing.com/resources/publish-or-perish

Harzing, A. W. (2017, 16 de março). Google Scholar is a serious alternative to Web of Science. LSE Impact Blog. https://blogs.lse.ac.uk/impactofsocialsciences/2017/03/16/google-scholar-is-a-serious-alternativeto-web-of-science

Harzing, A. W., \& Alakangas, S. (2015). Google Scholar, Scopus and the Web of Science: A longitudinal and cross-disciplinary comparison. Scientometrics, 106(2), 787-804. https://doi.org/10.1007/s11192-015-1798-9

Martín-Martín, A., Orduna-Malea, E., Thelwall, M., \& Delgado López-Cózar, E. (2018). Google Scholar, Web of Science, and Scopus: A systematic comparison of citations in 252 subject categories. Journal of Informetrics, 12(4), 1160-1177. https://doi.org/10.1016/j.joi.2018.09.002

Merton, R. K. (1973). The sociology of science: Theoretical and empirical investigations. University of Chicago Press.

Mosco, V. (2009). The political economy of communication (2. ${ }^{\text {a }}$ ed.). Sage. 
Oliveira, R. L. (2017). Órfãos de Jeffrey Beall: Revistas predatórias e outras iniciativas igualmente perniciosas para a pesquisa. Ciência e Cultura, 69(4), 4-5. https://doi.org/10.21800/2317-66602017000400002

Pivetta, M., \& Marques, F. (2012, setembro). Bruce Alberts: Ensinar ciência é preciso. Revista Pesquisa FAPESP, 199. https://revistapesquisa.fapesp.br/2012/09/14/bruce-alberts-ensinar-ciencia-e-preciso/

Sample, I. (2012, 24 de abril). Harvard University says it can't afford journal publishers' prices. The Guardian. https://www.theguardian.com/science/2012/apr/24/harvard-university-journal-publishers-prices

Suber, P. (2012). Open access. The MIT Press.

Suber, P. (2015, 5 de dezembro). Open access overview: Focusing on open access to peer-reviewed research articles and their preprints. http://legacy.earlham.edu/ peters/fos/overview.htm

Taberner, R. (2018). Métricas alternativas: Más allá del factor de impacto. Actas Dermosifiliográficas, 109(2), 95-97. https://doi.org/10.1016/j.ad.2018.01.002

Tsoukala, V., \& Angelaki, M. (2015). Diretrizes para políticas de acesso aberto para instituições que realizam investigação científica. PASTEUR4OA. http://www.pasteur4oa.eu/sites/pasteur4oa/files/resource/Diretrizes\%20para\%20Politicas\%20de\%20Acesso\%20Aberto_Set2015.pdf

UC Office of the President. (2019, 28 de fevereiro). UC terminates subscriptions with world's largest scientific publisher in push for open access to publicly funded research [Press release]. https://www.universityofcalifornia.edu/press-room/uc-terminates-subscriptions-worlds-largest-scientific-publisher-push-open-access-publicly

Zuckerman, H., \& Merton, R. K. (1971). Patterns of evaluation in science: institutionalisation, structure and functions of the referee system. Minerva, 9(1), 66-100. https://doi.org/10.1007/bf01553188 